\title{
O USO DOS PRONOMES TU E VOCE EM TEXTOS ORAIS DA CIDADE DE SANTARÉM
}

\author{
Ediene Pena FERREIRA \\ Campus Universitário de Santarém/UFPA \\ edienepena@ufpa.br
}

\begin{abstract}
Resumo: Este trabalho é o resultado de uma pesquisa de campo realizada no município de

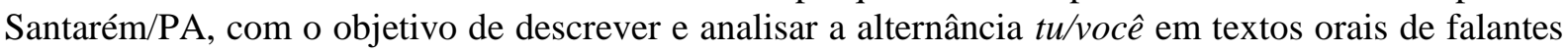
santarenos. Os dados foram coletados através de observações assistemáticas e utilizamos pressupostos teóricos da sociolingüística, mais especificamente, a teoria da variação lingüística. Referendamos nossa pesquisa com dados de alguns trabalhos sobre o tema que contemplam várias cidades brasileiras, demonstrando o uso variado dos referidos pronomes no Brasil. Nossos dados são constituídos por 110 ocorrências de $t u$, você, e a variante $c \hat{e}$, produzidas por 21 informantes. Foram consideradas em nossa análise as variáveis, faixa etária e relação entre os interlocutores, as quais se mostraram relevantes nos resultados. Constatamos que desses pronomes o mais utilizado pelos santarenos é o $t u$, o qual expressa intimidade e solidariedade entre os falantes. Já o pronome você indica formalidade e polidez.
\end{abstract}

Palavras-chave: Tu. Você. Variação linguística.Textos orais.

Abstract: This paper is the result of a local research conducted in the municipality called Santarém/PA, with the objective to describe and analyze the alternation TU/VOCE $\hat{E}$ in oral texts of speakers from Santarém. Data were collected through asystematic observations. We use theoretical assumptions of sociolinguistics, more specifically, the theory of linguistic variation. We countersigned our research with data from some studies on the subject which include several Brazilian cities, demonstrating the varied use of pronouns used in Brazil. Our data consists of 110 occurrences of "TU", "VOCÊ", and variant "CÊ", produced by 21 informers. It was considered in our analysis of the variables sex, age and relationship between the interlocutors. We noticed, in our corpus, which of these pronouns the most used by natives from Santarém is "TU", which expresses solidarity and intimacy among the speakers. Although, the pronoun "VOCE" indicates formality and politeness. Keywords: Tu. Você. Linguistic variation. Oral texts.

\section{Introdução}

A língua portuguesa corrente no Brasil dispõe de diferentes formas de tratamento para nos dirigirmos às pessoas, as mais utilizadas são: $t u$, você, senhor (a). $\mathrm{O}$ uso desses pronomes varia em cada região brasileira, em algumas comunidades lingüísticas, como é o caso da santarena, o $t u$ (concordando com o verbo em terceira pessoa) é empregado em situações comunicativas informais, expressando intimidade entre os interlocutores e o você indica formalidade, distanciamento. Em Belém, é comum que se considere a predominância do uso do $t u$ estabelecendo a concordância verbal, conforme prescrição da gramática normativa.

Houve a curiosidade em verificar a procedência dessa variação, para registrá-la cientificamente, mesmo que de forma não aprofundada, pois, dentre alguns estudos sobre esse assunto, não detectamos nenhuma divulgação acerca dessa abordagem tendo como fonte de 
pesquisa a cidade de Santarém/PA. Este trabalho tem como objeto de estudo a alternância tu/você em textos orais produzidos pelos santarenos, com o propósito de descrever e analisar a variedade lingüística da cidade, no que diz respeito ao uso da segunda pessoa do singular. Para tanto, a análise dos dados está fundamentada em três hipóteses: a alternância tu/você na fala dos santarenos não é uma escolha aleatória, mas é influenciada principalmente pelos fatores sociais, idade dos interlocutores e relação entre eles; em Santarém, quanto à referência à segunda pessoa do singular na fala, predomina o pronome $t u$, concordando com o verbo na terceira pessoa do singular; de um modo geral, o uso do pronome $t u$ expressa intimidade entre os interlocutores, e o uso do pronome você expressa pouca ou nenhuma intimidade.

Para comprovarmos ou refutarmos as hipóteses formuladas, constituímos uma amostra de corpus com 110 ocorrências produzidas por 21 informantes. O resultado da pesquisa é exposto neste artigo cuja organização é a seguinte: Na primeira seção apresentamos pressupostos teóricos da sociolingüística e sobre a relação entre interlocutores: a teoria do poder, solidariedade e polidez; na segunda, alguns trabalhos acerca do uso dos referidos pronomes; e na terceira, a pesquisa de campo (descrição e análise dos dados).

\section{A relação linguagem e sociedade: uma preocupação da sociolingüística}

A Sociolingüística é a área de estudo que investiga a relação entre linguagem e sociedade, mais especificamente, correlaciona a linguagem a fatores sociais como idade, sexo, classe social, escolaridade, profissão, relação entre interlocutores e contexto em que ocorre a interação verbal. Alkmim (2004, p. 31) define a Sociolingüística como "o estudo da língua falada, observada, descrita e analisada em seu contexto social, isto é, em situações reais de uso."

Seus pressupostos estão fundamentados na teoria da variação lingüística, “[...] um modelo teórico-metodológico que assume o 'caos' lingüístico como objeto de estudo [...]" (TARALLO, 1994, p. 6). O conceito de variação linguiística está ligado à noção de heterogeneidade, pois se varia a língua é porque esta não é homogênea. Tal fenômeno ocorre em todos os aspectos da língua, daí a seguinte classificação: variação fonético-fonológica; variação morfológica; variação sintática; variação semântica; variação lexical; e variação estilístico-pragmática.

William Labov, o grande responsável pelo avanço dessa corrente de estudo, defendeu que a variação lingüística deveria ser descrita, analisada e sistematizada, para tanto propôs um 
modelo de análise lingüística denominado "Sociolingüística Quantitativa", em que a sistematização das variações da língua falada baseia-se em dados estatísticos.

Uma das distinções feitas pelos sociolingüistas é a entre variantes e variáveis, "uma variável sociolingüística [...] é algum elemento da língua, alguma regra, que se realiza de maneiras diferentes, conforme a variedade lingüística analisada. Ao enquadrarmos o nosso objeto de estudo apresentado, nessa dicotomia, temos a variável "referência a segunda pessoa do singular" e as variantes os pronomes (1) tu; (2) você; e (3) cê.

A variação lingüística ou, conforme Bagno (2007), "variação sociolingüística” é classificada como: variação diatópica, vista como a diferença nos modos de falar que se verifica de uma cidade para outra, de uma região pra outra; variação diastrática, a que ocorre entre os diferentes modos de falar das diversas classes sociais; variação diamésica, a que se verifica na comparação entre língua falada e língua escrita; variação diafásica, a variação estilística da fala de cada pessoa, os variados modos de fala que ela realiza de acordo com o grau de monitoramento que atribui ao seu comportamento verbal, o qual é influenciado por fatores extralingüísticos (classe social, idade, sexo, situação em ocorre a interação etc.); variação diacrônica, que se constata na comparação de diferentes etapas da história de uma língua.

As discussões da sociolingüística vêm ao encontro de nossos interesses ao pesquisarmos a alternância $t u / v o c e ̂$ na fala santarena, por isso esta pesquisa está abrigada nesse paradigma de investigação, cuja preocupação, entre outras, é a relação entre interlocutores.

\subsection{Relações entre interlocutores: poder, solidariedade e polidez}

Nas relações interpessoais que estabelecemos todos os dias, a forma pronominal de tratamento com que nos dirigimos às pessoas é resultado da visão que temos dos interlocutores, demonstrando respeito ou desrespeito. Assim, em uma conversa entre pais e filhos, o poder que os pais têm em relação aos filhos é refletido na linguagem, por isso, geralmente utilizam o $t u$ ao se comunicarem com estes e são tratados por senhor (a) ou você. Nas relações profissionais, também, o poder é determinante na forma de tratamento, considerando-se a hierarquia profissional, assim, o chefe geralmente trata os funcionários por tu e tende a receber você ou senhor.

Um ponto interessante, para se entender o que está por trás dos modos de falar das pessoas, é que 
as relações interpessoais, de um modo geral, consideram a existência de um fator preponderante com base no qual o falante se posiciona frente ao seu ouvinte. Este fator é a simetria, que é estabelecida com base em uma hierarquia institucional ou negociada em uma situação interacional, conforme os interlocutores estabelecem suas identidade. (LUCCA, 2005, p. $62)$.

$\mathrm{Na}$ linguagem, a assimetria pode ser percebida quando dois falantes usam pronomes diferentes um para com o outro, como ocorre entre falantes de diferentes faixas etárias ou posição social.

Lucca (2005) aborda os itens poder, solidariedade, e polidez na interação verbal, baseando-se no estudo de Brown \& Gilman (1960), os quais relacionaram esses conceitos ao uso dos pronomes T/V ( $t u$ e vos do latim) em línguas européias (tu/vous - francês; tu/voi (Lei) - italiano; tu/vos (usted) - espanhol; du/lhr - alemão), que, em português, correspondem às formas tu e você; você e cê; ou você e senhor.

A noção de poder pode ser identificada como manifestação do controle que uma pessoa tem sobre outra em uma determinada interação social e pode ser observada na relação estabelecida entre falantes de diferentes idades, classes sociais, gêneros ou posição hierárquica.

A solidariedade ocorre entre interlocutores que pertencem à mesma faixa etária, à mesma classe social, e nenhum exerce poder sobre o outro, consideram-se iguais. Nesse caso tendem a se tratar utilizando o mesmo pronome ( $t u$ ou você), como ocorre entre amigos, irmãos, etc. Mas interlocutores que pertencem a diferentes faixas etárias, também podem se comunicar de forma solidária.

A polidez é revelada quando tratamos o interlocutor com cortesia, delicadeza ou carinho, noção essa expressa pelo pronome você.

De um modo geral, nas relações simétricas, os interlocutores são solidários; e nas assimétricas, um exerce poder sobre o outro. Dessa forma, estas são estabelecidas pelo poder, aquelas pela solidariedade.

\section{$2 \mathrm{O}$ uso dos pronomes tu e você: algumas investigações}

As referências que servem de base para o desenvolvimento deste trabalho são as pesquisas de Lucca (2005), Modesto (2006) e DIAS (2007). Lucca (2005) analisou a ocorrência da alternância tu/você em três regiões administrativas do Distrito Federal 
(Ceilândia, Taguatinga e Brasília), através de amostras provenientes de falantes adolescentes, do gênero masculino (apenas algumas meninas), estudantes de escolas públicas. Foram gravadas de forma oculta conversas entre os informantes e seus amigos da mesma faixa etária, também alunos de escolas públicas.

A autora correlacionou os dados às variáveis lingüísticas: paralelismo lingüístico; e tipo de estrutura; e sociais: gênero do falante; tipo de relação entre os interlocutores, familiaridade com o tema discursivo; e região administrativa do falante. Das referências à segunda pessoa do singular, o $t u$ corresponde a $72 \%$, enquanto o você a $28 \%$, confirmando a idéia de que nessas regiões o uso do tu está concentrado entre os rapazes, que segundo a autora expressa a noção de prestígio encoberto ${ }^{1}$.

Modesto (2006) estudou a alternância tu/você na cidade de Santos - SP, e, adotando como metodologia de pesquisa gravações secretas e não-secretas, obteve 20 inquéritos, os quais permitiram o autor concluir que $67 \%$ dos informantes preferem o pronome você, e $32 \%$ utilizam o $t u$, preferência essa confirmada pela análise dos fatores: gênero do falante: $67 \%$ dos homens e $65 \%$ das mulheres; escolarização (nível médio e nível superior): os santistas mais escolarizados tendem a usar menos a forma $t u$, dos que o utilizam, $40 \%$ tem o ensino médio, e 29\%, o ensino superior; e faixa etária: os dois grupos selecionados (15 a 20 anos; e de 21 anos em diante) representam o uso do você com $61 \%$ e $69 \%$, respectivamente.

Dias (2007), assim como Lucca, também estudou a fala brasiliense, mas tendo como enfoque o uso do pronome $t u$ entre moradores do Plano Piloto de Brasília. Os dados foram coletados através de gravações ocultas de conversas espontâneas, oriundos de dezoito informantes distribuídos nas faixas etárias de 13 a 19 anos; de 20 a 29 anos; e mais de 30 anos, sendo três falantes de cada sexo em cada faixa etária.

Diferentemente de Lucca que realizou uma pesquisa homogênea, já que buscou amostras somente em contextos favoráveis ao uso do $t u$, Dias (2007) coletou dados tanto em situações favoráveis como desfavoráveis a tal ocorrência pronominal. Assim, verificou a ocorrência de quatro formas de referência à segunda pessoa, tu, cê, você, e a referência nula, constatando que o pronome mais utilizado para se referir à segunda pessoa do singular é cê e sua forma plena você, no entanto, o tu é fortemente usado em Brasília pelos mais jovens, principalmente pelos rapazes, confirmando os resultados de Lucca.

\footnotetext{
1 Segundo Lucca, a expressão prestígio encoberto refere-se a variedades lingüísticas não padrão que adquirem uma espécie de 'prestígio', principalmente nas classes sociais mais baixas e entre os homens.
} 
De acordo com Dias, em Brasília o tu tende a ser usado em situações em que o falante deseja expressar um grau máximo de intimidade com seu interlocutor ou desrespeito, sendo que o tipo de relacionamento mais favorável ao uso do tu é o de amigo íntimo ou entre familiares.

Loregian (1996, apud LUCCA, 2005; MODESTO, 2006) desenvolveu o tema "Concordância verbal com o pronome tu na fala do sul do Brasil", analisando amostras do projeto VARSUL (dados de entrevistas realizadas em Florianópolis - dando ênfase a um vilarejo isolado, Ribeirão da Ilha - e Porto Alegre). Quanto às variáveis sociais, foram destacadas a região, a faixa etária (25 a 49, e mais de 50) e a escolaridade ( $1^{\circ}$ e $2^{\circ}$ ciclo do ensino fundamental, e ensino médio), as quais foram cruzadas com as localidades.

De forma geral, foi detectado que o nível escolar médio é o mais favorável à concordância canônica do pronome $t u$, concluindo-se que as pessoas mais escolarizadas têm mais tendência em estabelecer essa concordância, com exceção de Porto Alegre, pois nessa região os falantes utilizam mais a concordância verbal padrão com o $t u$ no primeiro ciclo do ensino fundamental. Em relação à faixa etária os dois grupos selecionados desfavorecem a referida concordância, no entanto, comparando-os, a faixa etária acima dos 50 anos é mais favorável.

Considerando essas pesquisas, é explícita a variação diatópica da língua portuguesa falada no Brasil, quanto ao uso dos pronomes tu e você. Assim, conforme o enfoque de estudo dado a esses pronomes, foi constatado que em algumas regiões como o Sul, e nas cidades Rio de Janeiro, João Pessoa e Belém o tu predomina, de forma peculiar, no Sul esse pronome é usado com mais freqüência que nessas três cidades. Enquanto os cariocas e os pessoenses não estabelecem a concordância verbal canônica, na capital paraense é comum essa concordância. Já em São Paulo e Brasília prevalece o você. Esses resultados nos instigam a investigar o comportamento lingüístico do falante santareno.

\section{Pesquisa de campo}

\subsection{Descrição do corpus}

A pesquisa sociolingüística apresentada neste artigo teve como fonte de investigação a fala espontânea dos santarenos. O método de coleta de dados adotado foi a realização de observações assistemáticas. Tal pesquisa ocorreu no período de outubro a novembro de 2008 , e o corpus é proveniente de 21 informantes, 10 homens e 11 mulheres, santarenos, agrupados 
nas faixas etárias 20 a 30; 31 a 45; e 46 em diante. Para não causar um desequilíbrio nos resultados e como uma de nossas suposições se refere ao uso do tu entre pessoas que se conhecem, e do você entre desconhecidos, tais falantes foram divididos em dois grupos: o dos que conhecem seu interlocutor; e o dos interlocutores que não se conhecem (no caso o informante e a pesquisadora).

O primeiro grupo é formado por 15 pessoas, cada faixa etária representada por 5 (quantidade mínima para cada célula combinada, segundo Tarallo), enquanto que o segundo é constituído apenas por 6 , sendo 2 em cada faixa etária.

A coleta ocorreu da seguinte forma: a pesquisadora observou a produção textual oral de santarenos. E logo após a constatação do uso dos pronomes $t u$, você ou cêe, as ocorrências foram transcritas, da forma mais fiel possível à fala dos informantes. Na maior parte dos registros a pesquisadora atuou como interlocutora do diálogo, contudo, não foram contabilizados os pronomes supracitados ocorrentes em sua fala.

Acerca dos falantes que se conhecem, apenas alguns nasceram no interior do município, mas já residem na cidade há muito tempo, desde quando crianças ou jovens (na situação desses últimos enquadram-se os informantes da faixa etária dos 60 anos, que já residem na cidade há quase quarenta 40 anos). Já sobre os desconhecidos, têm-se poucas informações, o sexo, e a idade foi deduzida.

A maioria dos informantes que conheciam seus interlocutores foi observada em contextos diferentes. Já quanto aos desconhecidos, cada informante foi observado em uma única situação. Além disso, a pesquisa ocorreu principalmente no ambiente familiar e no ambiente de trabalho, no caso dos interlocutores que se conheciam, e em locais públicos entre aqueles que não se conheciam.

Para análise, foram considerados relevantes os fatores sociais, idade dos interlocutores e tipo de relação entre eles. E, quanto ao número de ocorrências da variável em estudo, conforme as tabelas abaixo, foram registradas 110 ocorrências (90 entre interlocutores conhecidos - Tabela 1 - e 20 entre desconhecidos - Tabela 2) incluindo a variante $c \hat{e}$, confirmando-se a predominância do pronome $t u$.

Tabela 1: O uso das variantes $t u$, você e $c \hat{e}$ por interlocutores que se conhecem 


\begin{tabular}{|l|c|c|c|c|c|}
\hline \multicolumn{3}{|c|}{ Informantes } & \multicolumn{3}{c|}{ Variantes } \\
\cline { 1 - 6 } Faixa & \multicolumn{2}{|c|}{ Sexo } & \multirow{2}{*}{ Tu } & Você & cê \\
\cline { 2 - 6 } & M & F & & & \\
\hline $20-30$ & 3 & 2 & 19 & 7 & 3 \\
\hline $31-45$ & 2 & 3 & 37 & 2 & 0 \\
\hline +45 & 2 & 3 & 17 & 4 & 1 \\
\hline Subtotal & 7 & 8 & 73 & 13 & 4 \\
\hline TOTAL & \multicolumn{2}{|c|}{15} & \multicolumn{3}{|c}{90} \\
\hline
\end{tabular}

Na tabela 01, apresentamos as quantidades de ocorrências das variantes $t u$, você e $c \hat{e}$ produzidas por 15 informantes que conhecem seus interlocutores, totalizando 90 ocorrências, distribuídas de acordo com a faixa etária dos falantes. É evidente a predominância do pronome tu sendo usado com mais freqüência por falantes da faixa etária de 31 a 45 anos de idade. Mas não consideramos significativa essa diferença entre os grupos etários analisados, pois tal diferença se deu em virtude de mais convivência com alguns informantes dessa faixa etária.

Tabela 2: $\mathrm{O}$ uso das variantes $t u$, você e $c \hat{e}$ por interlocutores que não se conhecem

\begin{tabular}{|c|c|c|c|c|c|}
\hline \multicolumn{2}{|c|}{ Informantes } & \multicolumn{3}{c|}{ Variantes } \\
\hline \multirow{2}{*}{$\begin{array}{c}\text { Faixa } \\
\text { etária }\end{array}$} & \multicolumn{2}{|c|}{ Sexo } & Tu & Você & cê \\
\cline { 2 - 6 } & M & F & & & \\
\hline $20-30$ & 1 & 1 & - & 7 & - \\
\hline $31-45$ & 1 & 1 & - & 4 & - \\
\hline
\end{tabular}




\begin{tabular}{|c|c|c|c|c|c|}
\hline+45 & 1 & 1 & 9 & - & - \\
\hline Subtotal & 3 & 3 & 9 & 11 & - \\
\hline TOTAL & \multicolumn{2}{|c|}{6} & \multicolumn{3}{|c|}{20} \\
\hline
\end{tabular}

Na tabela 02, na qual constam os números de ocorrências das variantes em estudo entre falantes que não se conhecem, o você é mais utilizado, com pouca diferença em relação ao $t u$. Tal diferença mínima talvez tenha ocorrido porque os falantes da faixa etária com maior número de referências à segunda pessoa do singular (com mais de 45 anos) utilizaram somente o $t u$. No entanto, com base em outras ocorrências que não incluímos em nosso corpus, devido ao fato de termos feito um recorte para sistematizar tais dados com o mesmo número de informantes em cada faixa etária, afirmamos que o você é predominante entre os santarenos que não se conhecem.

Na tabela 3, apresentamos a soma geral da quantidade de ocorrências das variantes analisadas.

Tabela 3: Total de ocorrências das variantes $t u$, você e $c \hat{e}$

\begin{tabular}{|l|c|c|c|}
\hline Pronomes & tu & você & cê \\
\hline Subtotal de ocorrências & 82 & 24 & 4 \\
\hline Total de ocorrências & \multicolumn{3}{|c|}{110} \\
\hline № de falantes & \multicolumn{3}{|c|}{21} \\
\hline
\end{tabular}

\subsection{Análise dos dados}

Conforme os dados observados, constatou-se que o pronome tu é utilizado, geralmente, entre falantes que se conhecem há bastante tempo, são íntimos, e há solidariedade entre eles, como ocorre entre irmãos, colegas, amigos, etc., revelando simetria entre falante e interlocutor, até mesmo em situações em que haja diferença de idade, de hierarquia, etc. Nas 
relações assimétricas, é empregado pelo "superior" ao "inferior" (classificação referente a poder, hierarquia profissional, faixa etária), por exemplo, pelos pais ao falarem com seus filhos, como consta na ocorrência 01 .

Informantes: I1 (Informante1): sexo feminino, 71 anos, dona-de-casa, aposentada, semianalfabeta; N (Neto de I1): sexo masculino, 12 anos, cursando $6^{\text {a }}$ série; e I2 (Informante 2, filha de I1 e mãe de N): sexo feminino, 44 anos, costureira, ensino médio.

Situação: Conversa após N chegar da escola.

I1: Eu quero que $\boldsymbol{t} \boldsymbol{u}$ vá depois lá no Pague Menos ((supermercado)) comprar um negócio pra tua mãe.

$\mathrm{N}$ : O quê?

I2: Crédito.

$\mathrm{N}$ : Poxa eu vim no sol quente!

I1: Mais tarde $\boldsymbol{t} \boldsymbol{u}$ vai antes de $\boldsymbol{t} \boldsymbol{u}$ ir joga bola.

Em relações assimétricas não observamos nenhuma ocorrência do $t u$ empregado por um "inferior" ao se referir a um "superior", devido ao fato de quase não termos observado esse tipo de contexto. Especificamente sobre a forma de tratamento empregada pelos filhos ao se dirigirem aos pais, com base em nosso conhecimento empírico, sabemos que geralmente é o pronome senhor (a). No entanto, existem alguns santarenos que usam "tu" ou "você" nessa situação. O que do nosso ponto de vista não revela falta de respeito, exceto quando são utilizados com esse propósito, mas sim expressa uma relação mais moderna e próxima entre pais e filhos, em que os pais não exigem que seus filhos os tratem por senhor $(a)$, e os filhos têm mais liberdade com os pais, ou seja, embora sejam sujeitos de uma relação reconhecida pela assimetria, os membros são solidários.

Detectamos casos em que, apesar de se conhecer a pessoa há pouco tempo, o fato de os interlocutores terem quase a mesma idade e exercerem a mesma profissão, os levam a se tratarem pela forma $t u$, como é possível observar na ocorrência 02. Essa forma de tratamento foi comum também em relações em que os interlocutores pertencem à mesma faixa etária, nas quais a diferença hierárquica entre eles, no ambiente de trabalho, não desfavorece a simetria lingüística. 
Interlocutores: I (Informante): sexo feminino, 28 anos, assistente administrativo, graduada; e P (Pesquisadora).

Situação: I e P são colegas de trabalho e estavam conversando no local de trabalho, quando $\mathrm{P}$ estava de férias.

$$
[\ldots]
$$

P: E aí muito trabalho?

I: Ah eu quero que $\boldsymbol{t} \boldsymbol{u}$ volte logo que tem muita coisa! Olha não sei como $\boldsymbol{t} \boldsymbol{u}$ dava conta sozinha.

$$
[\ldots]
$$

Quanto à forma de tratamento você, geralmente, os santarenos a consideram formal e indicativa de polidez, e por isso seu uso é restrito, mas também há aqueles que, em seu vocabulário, preferem o pronome você ao $t u$. Considerando essa visão, ao analisarmos os dados, constatamos que o pronome você é predominantemente usado de forma solidária em diálogos entre pessoas que não se conhecem. Também ocorre de forma não solidária, como na ocorrência 03, produzida por pessoas que se conhecem, mas não são íntimas (apesar de não estar expresso, P trata I por senhor). Além disso, é usado por pessoas que se conhecem há bastante tempo, como uma forma de tratamento carinhosa ou delicada. Vale ressaltar que entre os interlocutores conhecidos os mesmos informantes que utilizaram o você alternam essa forma com a variante $c \hat{e}$.

Interlocutores: I (Informante): sexo masculino, 64 anos, perito, graduado; e P (Pesquisadora).

Situação: Diálogo no local de trabalho.

I: Secretária!

P: Oi.

I: Você corrigi isso aqui pro seu amigo?

P: Daqui a pouco, que agora eu vou sair.

$$
[\ldots]
$$

No tratamento entre interlocutores que se conhecem verificou-se assimetria lingüística no uso do você e do cê entre um falante e seus interlocutores apesar das semelhanças sociais entre eles (faixa etária, profissão, etc.). $\mathrm{O}$ falante se dirige a tais interlocutores utilizando o pronome você e é tratado pelo pronome $t u$. Em relações assimétricas, verificamos o uso de tal pronome de "superior" para "inferior" empregado por uma pessoa idosa com um cargo 
elevado em relação ao da jovem interlocutora. E houve também uma ocorrência de "inferior" para "superior" (utilizado por um funcionário ao se dirigir ao seu chefe).

Já entre desconhecidos o uso do você predominou, embora os dois representantes da faixa etária "Mais de 45 anos", coincidência ou não, terem utilizado somente o pronome $t u$ ao se dirigirem à interlocutora. Esse uso pode ser explicado pela diferença de idade, pois a pesquisadora é jovem e os referidos falantes são adultos de meia-idade; ou talvez utilizem o pronome você apenas em outras situações ou este não faça parte do vocabulário deles.

Interlocutores: I (Informante): sexo masculino, 25 a 29 anos; e P (Pesquisadora).

Situação: Diálogo na parada de ônibus, enquanto P aguardava o ônibus e estava lendo um livro, I chegou e iniciou o diálogo.

I: O Diamantino ((ônibus)) já passou?

P: Já, mas tava muito cheio, o pessoal tava na porta e eu não tinha como me segurar com esse livro.

I: É, esse horário vem muito cheio porque o pessoal vai pra faculdade... Você vai pra faculdade?

P: Não.

I: Vai pra casa?

P: É.

Portanto, os fatores faixa etária e relação entre interlocutores influenciam o uso do pronome de segunda pessoa. Os interlocutores que têm a mesma idade e se relacionam de forma íntima geralmente usam o $t u$, e se o interlocutor for mais novo que o falante, é comum que este também use tal pronome. Caso tenham a mesma idade ou aproximada e não se conheçam, ou mesmo que se conheçam não tenham intimidade, os interlocutores tendem a usar o você.

Ainda em relação à idade, não detectamos diferenças relevantes entre as referidas faixas etárias, com exceção, nos diálogos entre desconhecidos, do fato de que em todas as faixas etárias selecionadas o você foi empregado, no entanto, como afirmamos anteriormente, dois informantes com uma diferença de idade significativa em relação à interlocutora utilizaram o $t u$, divergindo da tendência do uso do você. A partir dessas duas ocorrências, levantamos uma outra hipótese, a qual não poderemos comprovar neste trabalho por escassez de dados, a de que os falantes adultos de meia-idade quando se comunicam com jovens usam o $t u$ mesmo sem ter intimidade. 
Os dados nos possibilitaram confirmar a hipótese de que a alternância tu/você, em Santarém, é influenciada pelos fatores idade e relação entre os interlocutores. Podemos dizer que, de um modo geral, o tu é empregado por pessoas que se conhecem há bastante tempo e têm uma relação íntima, e geralmente são da mesma faixa etária ou o interlocutor é mais novo que o falante. Já o pronome você ocorre mais entre os santarenos que não se conhecem, expressando polidez.

A hipótese de que, em Santarém, predomina o uso do $t u$, concordando com o verbo na terceira pessoa do singular, também foi confirmada, conforme constam nas ocorrências 01 e 02: "tu vai" $e$ "tu dava", respectivamente. Vale ressaltar que o nosso corpus contém apenas duas ocorrências de concordância verbal padrão com o $t u$.

Confirmamos, conforme hipótese elaborada, que os santarenos utilizam freqüentemente o $t u$ ao se dirigirem às pessoas com quem eles têm intimidade, dentre os quais irmãos, amigos, colegas de trabalho. E o uso do você, na maioria das ocorrências, expressa uma relação distante entre os interlocutores, que é o caso de conversas entre pessoas desconhecidas, ou com pessoas que o falante conhece, mas com as quais não têm uma relação íntima.

\section{Conclusão}

Diante do uso variado dos pronomes tu e você no Brasil, constatamos que em Santarém/PA, assim como em outras cidades brasileiras, a alternância tu/você não é uma escolha aleatória do falante, mas é resultado da influência de fatores sociais que, no caso dos falantes santarenos, os mais relevantes são idade e tipo de relação entre os interlocutores.

Comparando os resultados de nossa pesquisa, com os referentes a outras cidades brasileiras, expostos na segunda seção deste artigo, detectamos semelhanças e divergências. Enquanto em Brasília, a variável sexo é determinante para o uso do $t u$, o qual é fortemente usado por falantes do sexo masculino, principalmente pelos jovens, em Santarém, tal variante prevalece tanto entre homens como entre mulheres, sem diferenças significativas quanto a esse uso entre falantes de diferentes idades.

Aproximando-se da realidade lingüística santarena, entre os paraibanos, o gênero do falante não é considerado um fator decisivo para tal variação. De acordo com Bezerra (1994), nessa região, o pronome $t u$ predomina em situações de intimidade e o você, em situações de não solidariedade. Outra semelhança considerável em relação à variação em estudo se refere a 
capital João Pessoa, Pedrosa (1999) constatou que a maioria dos pessoenses tende a não fazer a concordância verbal canônica em relação ao $t u$.

Uma das localidades do território brasileiro que mais divergem da alternância tu/você de Santarém/PA é São Paulo. Conforme Modesto (2006), na cidade de Santos/SP, o pronome de segunda pessoa mais utilizado é você.

Nas cidades sulistas investigadas por Loregian-Penkal (2004) também o tu impera e o pronome você fica restrito a algumas situações, com exceção de Florianópolis, onde o você é mais utilizado. Mas diferentemente do que ocorre em Santarém/PA, a variável sexo também é determinante, pois as mulheres são mais conservadoras em relação à tradição desse uso pronominal.

$\mathrm{Na}$ capital paraense é forte o uso do $t u$, no entanto diverge da realidade lingüística santarena em relação à concordância verbal estabelecida com esse pronome, pois em Belém é comum a concordância padrão, diferente do que ocorre entre os santarenos.

Dessa forma, os resultados sobre o uso dos pronomes $t u$ e você em textos orais da cidade de Santarém/PA podem assim ser resumidos: trata-se de uma variação diafásica (ou estilística), em que as referidas variantes são influenciadas de forma considerável pelos fatores faixa etária e tipo de relação entre interlocutores. O pronome mais utilizado na cidade para se referir ao interlocutor é o $t u$, o qual expressa intimidade e solidariedade entre os falantes. Além disso, como na maior parte do Brasil, não concorda de forma canônica com o verbo. Quanto ao pronome você, este indica formalidade e polidez, sendo preponderante o uso recíproco entre interlocutores que não se conhecem ou não têm intimidade.

\section{Referências}

ALKMIM, Tânia Maria. Sociolingüística. Parte I. In: MUSSALIM, Fernanda \& BENTES, Anna Christina. Introdução à Linguiística: domínios e fronteiras. v. 1. 4⿳亠丷a ed. São Paulo: Cortez, 2004, p. 21-47.

BAGNO, Marcos. Nada na língua é por acaso: por uma pedagogia da variação lingüística. São Paulo: Parábola Editorial, 2007, p. 27-57. 
DIAS, Edilene Patrícia. O uso do tu no português brasiliense falado. 2007. 104 f. Dissertação (Mestrado em Lingüística). Instituto de Letras/ UnB/Brasília. [mensagem pessoal]. Mensagem recebida por adrianalopes_ufpa@hotmail.com. Em 20 set. 2008.

LUCCA, Nívia Naves Garcia. A variação tu/você na fala brasiliense. 2005. 126 f. Dissertação (Mestrado em Lingüística). Instituto de Letras/UnB/Brasília. [mensagem pessoal]. Mensagem recebida por adrianalopes_ufpa@hotmail.com. Em 20 set. 2008.

MODESTO, Artarxerxes Tiago Tácito. Formas de tratamento no português brasileiro: A alternância tu/você na cidade de Santos/SP. 2006. 141 f. Dissertação (Mestrado em Letras). Faculdade de Filosofia, Letras e Ciências Humanas, USP, São Paulo. Disponível em: <http://www.teses.usp.br>. Acesso em 30 out. 2008.

TARALlO, Fernando. A Pesquisa Sociolingüística. 4ª ed. São Paulo: Ática, 1994. 